\title{
Multi-Factor Grey Correlation Analysis of Horizontal Well Development Effect in Chunguang Oilfield
}

\author{
Li Jiqiang, ${ }^{1, *}$, Yuan Yingzhong ${ }^{1}$, Niu Xiaofeng ${ }^{1}$, Yang Jianhui ${ }^{2}$ and Ren Jing ${ }^{2}$ \\ ${ }^{I}$ School of Oil and Gas Engineering, CQUST, Chongqing, 401331, P.R. China; ${ }^{2}$ Xinjiang Exploration \& Exploitation \\ Centre, Henan Oilfield Branch Company, CNPC, Yanqi, 841100, P.R. China
}

\begin{abstract}
Chunguang oilfield is a lithologic trap reservoir with edge water drive, whose horizontal well development effect is influenced by static factors and dynamic factors. In the process of production, the influences of static factors including reservoir physical properties and dynamic factors including working system, liquid production velocity on horizontal well development effects are different, and it is difficult to find main factor influencing horizontal well development effect with conventional single-factor analysis method. Combined with static and dynamic data of Chunguang oilfield, using multi-factor grey correlation analysis method, quantitative relationships between horizontal well development effect and different factors are systematically analyzed. Main factors influencing horizontal well development effect and dynamic influence laws between different factors and horizontal well development effect are clarified. Problems existed in the development process are known and it can provide the direction for future development and adjustment of Chunguang oilfield.
\end{abstract}

Keywords: Horizontal well, Development effect, Influence factors, Grey correlation, Permeability.

\section{INTRODUCTION}

Chunguang oilfield is a lithologic trap reservoir with edge water, whose oil area is small and edge water is active. Horizontal wells are used in many development units [1]. In the development process, water cut of horizontal well increases quickly, oil production rate decreases, sand production of formation is serious, and the development effect is bad. At present, main factors influencing horizontal well development effect is not clear.

Many scholars at home and abroad researched the factors influencing horizontal well development effect. The results indicated that there are many factors influencing horizontal well development effect including static factors and dynamic factors [2-8]. In the process of horizontal well development effect evaluation, it is found that single influence factors are insulated and it is difficult to find main factor influencing horizontal well development effect with conventional singlefactor analysis method. Therefore, it is needed to use proper method to analyze and correlate horizontal well development effect with multi-factors, find main factor and dynamic influence regulars of horizontal well development effect, make clear development adjustment direction, and establish foundation for improving horizontal well development effect.

\section{SINGLE-FACTOR ANALYSIS OF DEVELOPMENT EFFECT AND THE LIMITATIONS}

Based on Joshi's research achievement, deliverability formula of horizontal well can be expressed as [9]:

*Address correspondence to this author at the School of Oil and Gas Engineering, Chongqing University of Science \& Technology, Chongqing, 401331, P.R. China; Tel: +86 023 65022347; Fax: +86 023 65022247;

E-mail: lijiqiangcq@163.com

$$
Q_{0}=\frac{2 \pi k_{r o} k_{h} h \cdot \Delta p}{\mu_{0} B_{0}\left[\ln \frac{a+\sqrt{a^{2}-(L / 2)^{2}}}{L / 2}+\frac{\beta h}{L} \ln \left(\frac{\beta h}{2 \pi r_{w}}+s\right)\right]}
$$

where, $\beta=\sqrt{k_{h} / k_{v}}, R_{e h}=\sqrt{A / \pi}$

$$
a=\frac{L}{2} \sqrt{0.5+\sqrt{0.25+\left(2 R_{e h} / L\right)^{4}}} .
$$

$\mathrm{Q}_{\mathrm{o}}$-oil production rate of horizontal well, $\mathrm{m}^{3} / \mathrm{s} ; \mathrm{R}_{\mathrm{eh}}-$ oil drainage radius of horizontal well, $\mathrm{m} ; \mathrm{r}_{\mathrm{w}}-$ well radius of horizontal well, $\mathrm{m}$; L-length of horizontal well, $\mathrm{m}$; A-oil drainage area of horizontal well, $\mathrm{m}^{2} ; \mathrm{K}_{\mathrm{h}}, \mathrm{K}_{\mathrm{v}}$ horizontal and vertical permeability, $\mathrm{m}^{2} ; \mathrm{K}_{\mathrm{ro}}$-oil relative permeability, dimensionless; $\mathrm{h}$ - thickness of oil layer, $\mathrm{m}$; $\mathrm{a}$-semi-major axis of horizontal well drainage area, $\mathrm{m}$; $\mu \mathrm{o}$-formation oil viscosity, $\mathrm{Pa} \cdot \mathrm{s}$; Bo-formation oil volume factor, $\mathrm{m}^{3} / \mathrm{m}^{3} ; \mathrm{S}$-skin factor of horizontal well; $\Delta \mathrm{P}$-production pressure drop, $\mathrm{Pa}$.

From Eq. (1), we can know that oil production rate of horizontal well is related to oil layer's absolute permeability, relative permeability, thickness, production pressure drop, oil physical property, length of horizontal well section, drainage radius of horizontal well, heterogeneous coefficient and skin factor. These factors can be divided into natural geologic factors and development factors [10]. According to characteristics of the factors, they can also be divided into static and dynamic factors.

For a specific horizontal well, static parameters such as reservoir permeability, reservoir thickness, physical property of crude oil, length of horizontal well section, drainage radi- 


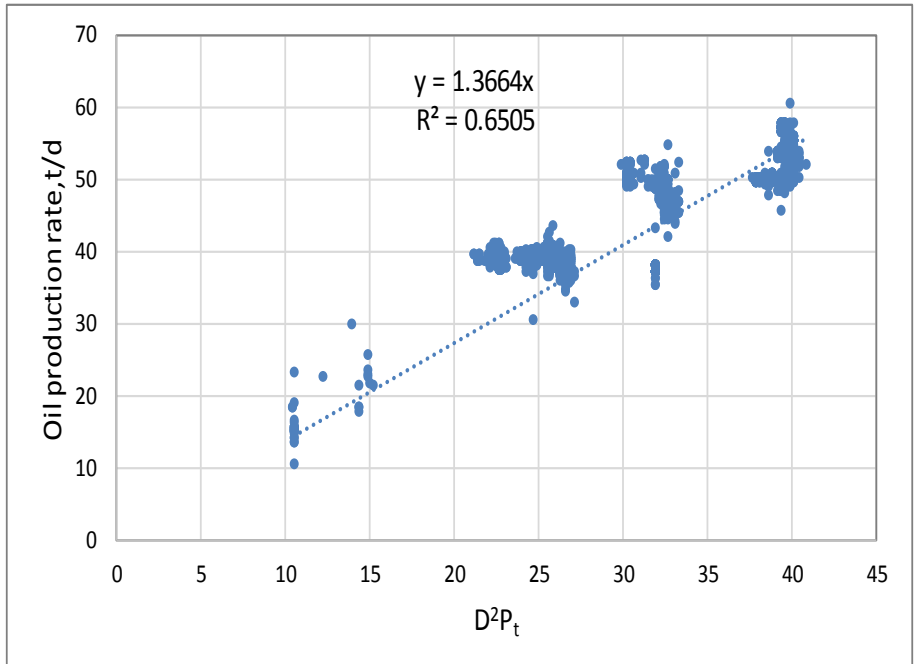

Fig. (1). Relationship between oil production rate and choke \& tubing pressure of well P2-P31 $\left(Q_{o}=1.3364 D^{2} \cdot P_{t}\right)$.

us of horizontal well, heterogeneous coefficient, skin factor et al. remain unchanged. Main parameters influencing oil production rate are producing pressure drop and oil phase relative permeability. Producing pressure drop are mainly affected by working system of individual well (or liquid producing rate of individual well) and liquid production rate of unit (or block). Oil phase relative permeability are mainly affected by water saturation. According to the theory of Buckley-Leverett, water saturation is related to water-cut. Therefore, oil production rate is related to liquid producing rate of individual well, liquid production rate of unit and water-cut and so on.

Usually, supposing that some natural flowing wells without water production has approximately same oil/gas ratio, and relative density of ground crude oil changes rarely, and surface tubing pressure (upstream pressure of choke) is twice as large as wellhead back pressure (downstream pressure of choke), there is an approximate relation between oil well production rate and oil pressure \& diameter of choke.

$Q_{0}=C D^{2} \cdot P_{t}$

Where, $\mathrm{Q}_{\mathrm{o}}$ is oil production rate, $\mathrm{t} / \mathrm{d}$; $\mathrm{D}$ is hole diameter of choke, $\mathrm{mm}$; $\mathrm{Pt}$ is tubing head pressure, $\mathrm{MPa} ; \mathrm{C}$ is choke factor.

In the production processes of Chunguang Oilfield, pressure maintenance degree is high, bottom hole flowing pressure of producing well is higher than saturation pressure, and production gas/oil ratio is the same as primary gas/oil ratio. According to oil production rate $\mathrm{Q}_{\mathrm{o}}$ of horizontal well before producing water, choke diameter $\mathrm{D}$ and tubing pressure $\mathrm{Pt}$, regression analysis result indicated that the relationship between $\mathrm{Q}_{0}$ and $\mathrm{D}^{2} \mathrm{Pt}$ is linear. According to Fig. (1), oil production rate increases along with the increase of choke diameter and tubing pressure. Through adjusting working system, the oil production rate can be adjusted, but daily oil production rate should be reasonable to prevent edge water advancing quickly.

Edge water advancing of a single horizontal well is not only influenced by individual well liquid producing rate (or working system) but also affected by liquid production velocity in the whole unit (or block). Where, liquid producing rate is daily produced liquid mass or volume and the liquid production velocity is the ratio of annual liquid volume to OOIP of unit. For example, the daily oil production rate of a single well P2-P89 is $25 \sim 30 \mathrm{t} / \mathrm{d}$. Besides, the liquid production velocity in the unit is more than $10 \%$ over a long period of time, as shown in Fig. (2). Oil production rate of single well and liquid production velocity of the unit can both lead to quick advancing of edge water. It is very difficult to distinguish whether oil production rate of single well or liquid production velocity in the unit is the main factor influencing advancing of edge water.

Initial oil production rate of horizontal well in Chunguang Oilfield is affected by static factors such as reservoir $\mathrm{kh}$ value, the length of horizontal well section $\mathrm{L}$ and so on. But in the process of long-term production, static factors and dynamic factors (such as working system and liquid production velocity) have different influences on development effect of horizontal wells. Only analyzing from single factor, it is difficult to identify whether large liquid production rate of single well or high liquid production velocity of unit causes advancing of edge water and decrease of oil production rate for horizontal well. Therefore, it is necessary to use multifactor correlation method to analyze development effect of horizontal wells.

\section{MULTI-FACTOR GREY CORRELATION ANALY- SIS}

\subsection{Grey Correlation Analysis Method}

The influencing factors for development effect of horizontal wells in Chunguang Oilfield are complex and numerous. It is significant for system analysis to analyze the correlation property among factors, to quantify the correlation degree, to sequence the correlation degree and to judge the dynamic correlation property. Grey correlation analysis is a statistic analysis technology, which is mainly used to analyze close degree between parent factors and sub-factors in the 


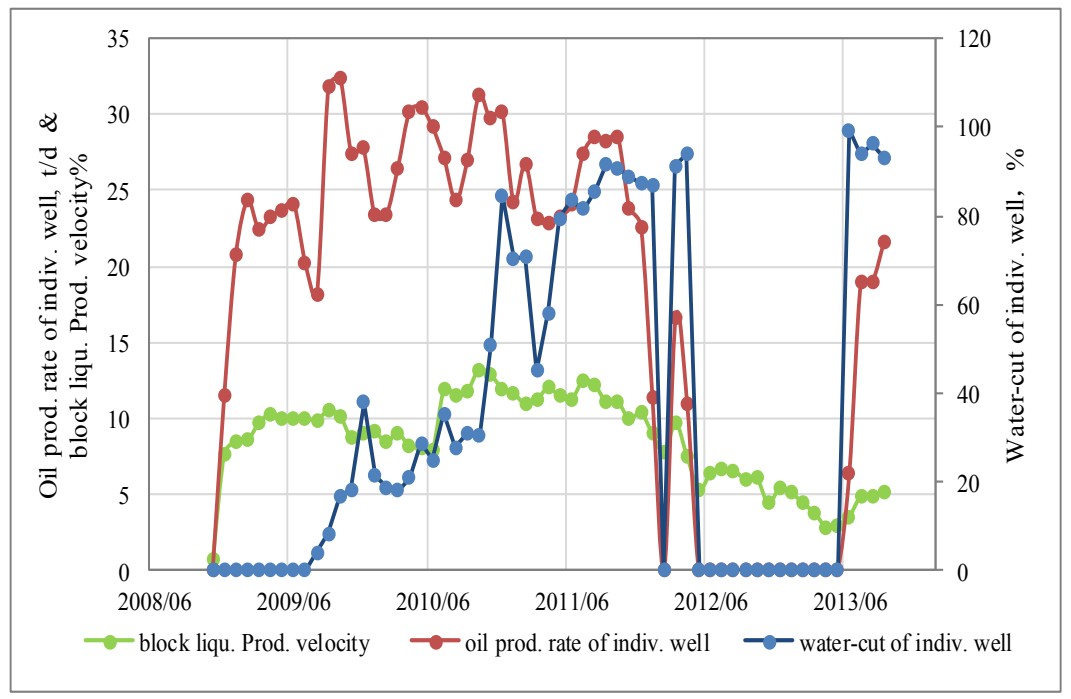

Fig. (2). Production index of well P2-P89 and liquid production velocity of unit.

system, and identify the major factors and secondary factors that lead to the development and changes of the system. Grey correlation analysis is a method that can quantify and compare system dynamic developing situation [11-13].

Suppose that reference array is $X_{0}=\left\{x_{0}(k), k=\right.$ $1,2, \cdots, n\}$, and the compared array (factor array) is $X_{i}=\left\{x_{i}(k), k=1,2, \cdots, n\right\}, \mathrm{i}=1,2, \cdots, \mathrm{m}$ so the grey correlation degree $\gamma\left(X_{0}, X_{i}\right)$ between $X_{0}$ and $X_{i}$ can be defined as the formula below:

$\gamma\left(X_{0}, X_{i}\right)=\frac{1}{n} \sum_{k=1}^{n} \gamma\left[x_{0}(k), x_{i}(k)\right]$

where,

$\gamma\left[x_{0}(k), x_{i}(k)\right]=\frac{\min _{i} \min _{i}\left|x_{0}(k)-x_{i}(k)\right|+\rho \max _{i} \max _{k}\left|x_{0}(k)-x_{i}(k)\right|}{\left|x_{0}(k)-x_{i}(k)\right|+\rho \max _{i} \max _{k}\left|x_{0}(k)-x_{i}(k)\right|}$

In the formula, $\rho$ is resolution coefficient, and $\rho \in[0,1]$, usually $\rho=0.5$. The correlation array assembly can be obtained by arranging $\mathrm{m}$ array correlation degrees $\gamma\left(X_{0}, X_{i}\right)$ from high to low. This can be used to identify the correlative degree between array $\mathrm{X}_{\mathrm{i}}$ and $\mathrm{X}_{0}$.

\subsection{Results of Grey Correlation Analysis}

The changes of oil production rate reflect the influences of many factors such as reservoir physical property, heterogeneity, development well network, liquid production velocity, working system and so on. Now take oil production rate in different time as reference array and take influence factors as compared array (factor array), at the same time adopt multi-factor grey correlation methods to analyze the main factors influencing oil production rate or development effect.

Take Well P2-P89 as an example. The reference arrays and factor arrays of each year is shown in Table 1. The annual oil production rate of a single well represents the changes of development effect. The annual liquid production rate represents the influences of working system of the well itself on oil production rate. Water-cut of single well represents the influences of well's water content change on oil production rate. Liquid production velocity of the unit represents the influences of producing environment in whole unit on oil production rate of single well. Thickness of oil layer " $h$ " (or other static information) represents the influence of static factors on oil production rate.

Calculate the correlation coefficient in each year according to grey correlation analysis (Table 2). The results of grey correlation analysis indicate:

$$
\gamma\left(X_{0}, X_{1}\right)>\gamma\left(X_{0}, X_{2}\right)>\gamma\left(X_{0}, X_{4}\right)>\gamma\left(X_{0}, X_{3}\right)
$$

Make a comprehensive rank for various influential factors of each year: single well working system (or liquid production rate) $>$ liquid production velocity of unit $>$ static geologic factor $>$ water-cut. Grey correlation factor in each year can also be seen from Table 2 and Fig. (3). For example, rank of influential factors in 2010 is that: static factors $>$ liquid production velocity of unit $>$ single well working system (or liquid production rate) $>$ water-cut.

According to the analysis results in Table 2, it is known that due to the large liquid production rate of well P2-P89, the edge water advances quickly and oil production rate drops. Liquid production velocity has also some influences on well P2-P89, but the influential degree is lower than liquid production rate of the well itself. For well P2-P89, the liquid production rate (or working system) is the main factor to influence the development effect. Therefore, it is supposed to maintain reasonable working system, to prevent edge water advancing quickly, to prevent water-cut increasing quickly, and improve the development effect of horizontal wells.

\section{CONCLUSION}

1. On the condition that static parameters do not change, oil production rate is mainly influenced by dynamic factors such as liquid production rate of single well (or working system), liquid production velocity of unit, water-cut and so on. Through multi-factor grey correlation analysis and grey correlative degree calculation, the influential degree of various factors can be analyzed quantitatively, and the main factors 
Table 1. Grey correlation analysis data of well P2-P89 (take oil production rate of single well as the reference array).

\begin{tabular}{|c|c|c|c|c|c|}
\hline Year & 2008 & 2010 & 2011 & 2012 & 2013 \\
\hline Annual oil production rate of single well $(\mathrm{x} 0), \mathrm{t} / \mathrm{a}$ & 8265.5 & 6727.8 & 1998.2 & 111 & 185.1 \\
\hline Annual liquid production rate of single well $(\mathrm{x} 1), \mathrm{t} / \mathrm{a}$ & 9366.8 & 10126 & 9234.4 & 1193.4 & 3737.8 \\
\hline Liquid production velocity of unit (x2), \% & 9.62 & 10.34 & 11.31 & 6.72 & 4.49 \\
\hline Water-cut of single well (x3), \% & 11.76 & 33.56 & 78.36 & 90.7 & 95 \\
\hline Thickness of oil layer $(\mathrm{x} 4), \mathrm{m}$ & 3.8 & 3.8 & 3.8 & 3.8 & 3.8 \\
\hline
\end{tabular}

Table 2. Grey correlation coefficient and grey correlation degree of well P2-P89 (take oil production rate of single well as the reference array).

\begin{tabular}{|c|c|c|c|c|c|c|}
\hline Year & $\mathbf{2 0 0 8}$ & $\mathbf{2 0 1 0}$ & $\mathbf{2 0 1 1}$ & $\mathbf{2 0 1 2}$ & $\mathbf{2 0 1 3}$ & $\mathbf{r}\left(\mathbf{x}_{\mathbf{0}}, \mathbf{x}_{\mathrm{i}}\right)$ \\
\hline \hline $\mathrm{r}[\mathrm{x} 0(\mathrm{k}), \mathrm{x} 1(\mathrm{k})]$ & 1 & 0.9378 & 0.8441 & 0.9725 & 0.9145 & 0.9413 \\
\hline $\mathrm{r}[\mathrm{x} 0(\mathrm{k}), \mathrm{x} 2(\mathrm{k})]$ & 1 & 0.9392 & 0.8118 & 0.8546 & 0.9006 & 0.9067 \\
\hline $\mathrm{r}[\mathrm{x} 0(\mathrm{k}), \mathrm{x} 3(\mathrm{k})]$ & 1 & 0.6638 & 0.3855 & 0.3435 & 0.3333 & 0.5451 \\
\hline $\mathrm{r}[\mathrm{x} 0(\mathrm{k}), \mathrm{x} 4(\mathrm{k})]$ & 1 & 0.9559 & 0.8416 & 0.8033 & 0.8047 & 0.8807 \\
\hline
\end{tabular}

influencing oilfield development effect of horizontal wells can be obtained.

2. For horizontal wells in Chunguang oilfield, it is supposed to maintain reasonable working system and unit liquid production velocity to prevent edge water advancing quickly and delay decline of oil production rate, and improve the development effect of horizontal wells.

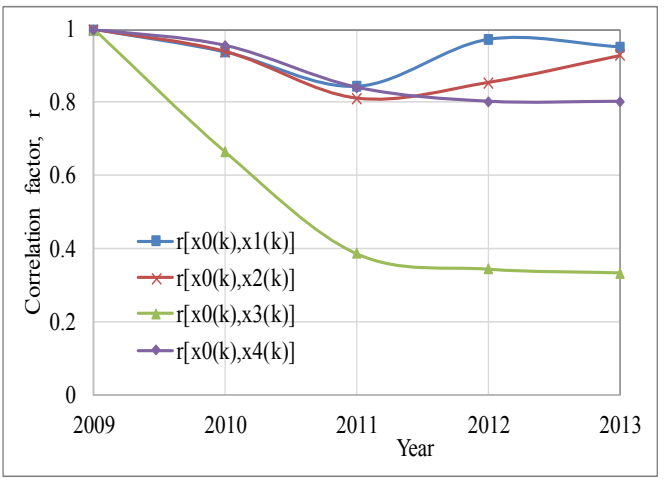

Fig. (3). Changes of grey correlation coefficient.

\section{CONFLICT OF INTEREST}

The author confirms that this article content has no conflict of interest.

\section{REFERENCES}

[1] L. Chuanhu, and W. Xuezhong, "Chunguang special development technology for the lithologic reservoirs driven by edge water in the Chunguang oilfield", Special Oil \& Gas Reservoirs, vol. 18, no. 2, pp. 52-55, 2011
[2] Z. Junde, and G. Chaoyang, "Numerical simulation of watered-out mechanism in horizontal well", Acta Petrolei Sinica, vol. 27, no. 5 , pp. 99-102, 2006.

[3] H. Xianke, "Analysis on influential factors of water flooding development efficiency in Block A31", Fault-block Oil \& Gas Field, vol. 15 , no. 1 , pp. $72-74,2008$.

[4] C. Liying, L. Huiqing, and Z. Zongyuan, "Research on law of water breakthrough and water control for horizontal well in edge water reservoir", Fault-block Oil \& Gas Field, vol. 17, no. 4, pp. 448-450, 2010.

[5] R. Liangyu, W. Xianghong, and L. Xianbing, "Development effect evaluation and strategy of horizontal wells in multilayer edge water reservoir in Sudan", Lithologic Reservoirs, vol. 23, no. 5, pp. 106 $110,2011$.

[6] L. Hongdan, "Influential factor analysis on ultra-thick oil reservoir horizontal development effect", Journal of Yangtze University (Natural Sciences), vol. 9, no. 12, pp. 84-85, 2012.

[7] Y. Xiaomei, "Influential factor of development effect and optimization of horizontal well for low-efficiency heavy oil reservoir", Fault-block Oil \& Gas Field, vol. 19, no. 1, pp. 25-27, 2012.

[8] Q. Yaguang, A. Guirong, and Z. Wensheng, "The analysis of influencing factors on development of horizontal wells in bottom water drive reservoir", Science Technology and Engineering, vol. 13, no. 12, pp. 3406-3408, 2013.

[9] S.D. Joshi, "Augmentation of well productivity using slant and horizontal wells", SPE15375, 1988.

[10] Y. Haining, W. Junlai, and L. Jiaxu, "On factors affecting the development of horizontal well", Journal of Chongqing University of science and Technology (Natural Sciences), vol. 13, no. 5, pp. 1-4, 2011.

[11] D. Julong, "The theory and method of social economic grey system", China Social Sciences, no. 6, pp. 47-60, 1984.

[12] L. Xiuhong, "A model based on the grey relation grade for multiobjective decision-making and its application", Journal of Shandong University (Natural Science), vol. 42, no. 12, pp. 33-36, 2007.

[13] L. Yiyang, "Grey correlation analysis on industrial structure and economic growth in Gansu province", Enterprise Strategy, no. 5, pp. 20-23, 2011

Received: April 17, 2015

Revised: May 21, 2015

Accepted: May 26, 2015

(C) Jiqiang et al.; Licensee Bentham Open.

This is an open access article licensed under the terms of the Creative Commons Attribution Non-Commercial License (http://creativecommons.org/licenses/by-nc/4.0/) which permits unrestricted, non-commercial use, distribution and reproduction in any medium, provided the work is properly cited. 